\title{
ANÁLISE DE UM EVENTO SINGULAR DE INTERAÇÃO MÃE-CRIANÇA NA CONSTITUIÇÃO DE UM SENTIDO PARA A ESCRITA
}

\author{
Maria Laura Trindade Mayrink-Sabinson
}

RESUMO: In this paper, which shares the theoretical and methodological assumptions of the
Integrated Project CNPq "The theoretical relevance of singular data in the acquisition of
written language", a singular event of mother and pre-school child interaction is analysed as
to the way adult and child act in constituting meaning to writing with the objetive of discussing
the theoretical status to be attributed to the OTHER/interlocutor in the process of written
language acquisition. The analysis shows that the SUBJECT/OTHER is in constant movement
be it a child in search of authonomy or a literate adult. It also shows that the movement of the
SUBJECT/OTHER affects the movement of the OTHER/SUBJECT whom he encounters and
with whom he confronts in the process of interlocution. Theories which aim to explain the
process of written language acquisition should not only attribute a constitutive role to the
OTHER/interlocutor but also allow an explanation of this movement of reciprocal constitution.

PALAVRAS-CHAVE: aquisição da escrita, interação, interlocução, papel do OUTRO/interlocutor.

1. Este trabalho insere-se nas preocupações teórico-metodológicas do Projeto Integrado $\mathrm{CNPq}$ A relevância teórica dos dados singulares na aquisição da linguagem escrita, constituindo-se num subprojeto intitulado $O$ papel do interlocutor na constituição da escrita pela criança, em que a questão que se coloca é a de discutir que estatuto teórico atribuir ao interlocutor, adulto letrado, no processo de aquisição da representação escrita pela criança.

2. Teorias que se pretendem como explicativas do processo de aquisição da linguagem escrita, como a psicogênese de Emília Ferreiro ou o sócio-interacionismo de Vygotsky, vêem de maneira diferente o papel do adulto letrado nesse processo de aquisição.

Em Ferreiro, quando muito, o papel do adulto é o de quem informa à criança sobre aspectos da escrita que não seriam dedutíveis do próprio objeto, tais como nomes de letras e sinais de pontuação, a distinção entre números/letras/sinais de pontuação, a orientação convencional da leitura. Aí, estaríamos "no terreno dos conhecimentos socialmente transmitidos, e altamente convencionais", cuja aquisição "requer condições sociais específicas" (FERREIRO, 1986, p. 61). O sujeito, em Ferreiro, é

o sujeito cognoscente, o sujeito que busca adquirir conhecimento, o sujeito que a teoria de Piaget nos ensinou a descobrir (...) um sujeito que procura ativamente compreender o mundo que o rodeia, e trata de resolver as interrogações que este mundo provoca. Não é um sujeito que espera que alguém que possui um conhecimento 
o transmita a ele (...) é um sujeito que aprende basicamente através de suas próprias ações sobre os objetos do mundo, e que constrói suas próprias categorias de pensamento, ao mesmo tempo que organiza seu mundo. (id., p. 26; a ênfase corre por minha conta).

Apesar de admitir que "o desenvolvimento da alfabetização ocorre, sem dúvida, em um ambiente social", Ferreiro ressalva que "as práticas sociais, assim como as informações sociais, não são recebidas passivamente pelas crianças (...) que necessariamente transformam o conteúdo recebido." (FERREIRO, 1987, p.24).

O trabalho desta autora focaliza e privilegia o conhecimento sobre o sujeito que constrói a linguagem e o desenvolvimento das habilidades cognitivas que interagem nesse processo de construção. Volta-se para mostrar as transformações efetuadas pelo sujeito nos estímulos oferecidos pelo ambiente, sobre os quais o sujeito age a partir de esquemas assimiladores já construídos. Esse sujeito piagetiano não é, no entanto, um sujeito individual mas, enquanto construto teórico, um sujeito idealizado, universal, que passa por etapas/estágios na construção do conhecimento. Embora o contexto esteja pressuposto, uma vez que a maturação de um organismo é entendida como ocorrendo em contextos específicos com os quais o sujeito interage continuamente, esse contexto não é visto como constitutivo do processo de aquisição. Seu eventual papel mediador não é teoricamente explorado. O mesmo pode ser dito do papel do interlocutor, do OUTRO que interage com a criança, visto como um elemento a mais no contexto social em que a construção do conhecimento sobre o objeto se dá.

Já Vygotsky afirma que:

from the very first days of the child's development his activities acquire a meaning of their own in a system of social behavior and, being directed towards a definite purpose, are refracted through the prism of the child's environment. The path from object to child and from child to object passes through another person. (VYGOTSKY, 1978, p.30; a ênfase é minha).

Este autor atribui, assim, um papel ao OUTRO, interlocutor da criança, afirmando que a imitação e a instrução precedem o desenvolvimento:

In the child's development (...) imitation and instruction play a major role. They bring out the specifically human qualities of the mind and lead the child to new developmental levels. In learning to speak, as in learning in school subjets, imitation is indispensable. What the child can do in cooperation today he can do alone tomorrow. (id., p.30).

O papel do OUTRO, então, seria o de prover o que seria imitado, incorporado pela criança, num momento de seu desenvolvimento, e, mais tarde, internalizado por ela, transformado e modificado como novo conhecimento. Quando Vygotsky, ao discutir a noção de mediação, descreve o desenvolvimento do gesto de apontar, fica bem claro o papel do adulto, na seguinte passagem:

When the mother comes to the child's aid and realizes his movements indicates something, the situation changes fundamentally. Pointing becomes a gesture to others. The child's unsuccessful attempt engenders a reaction not from the object he seeks but from another person. Consequently, the primary meaning of that unsuccessful grasping movement is established by others. (id., p. 56; ênfase do autor).

Ou seja, é o adulto, já inserido nas práticas sociais, quem atribui sentido aos movimentos da criança, transformando-os em gestos, e este sentido é posteriormente incorporado pela criança. "It becomes a true gesture only after it objectively manifests all the functions of pointing to others and is understood by others as such a gesture. Its meaning and functions are created at first by an objective situation and then by people who sorround the child." (id., p.56; a ênfase é minha).

Vygotsky acredita que a linguagem escrita, longe de ser uma habilidade motora complexa, é um sistema particular de símbolos e signos e que seria imprescindível entender a história de desenvolvimento simbólico na criança e o lugar da escrita nesse desenvolvimento para se chegar a uma solução correta sobre a psicologia da escrita. Essa história começaria 
com os gestos, passaria pelo simbolismo na brincadeira (games) e no desenho para desembocar na escrita. Falando dessa história de desenvolvimento das operações simbólicas o autor diz:

We have found that sign operations appear as a result of a complex and prolonged process subject to all the basic laws of psychological evolution. This means that signusing activity in children is neither simply invented nor passed down by adults, rather it arises from something that is originally not a sign operation and becomes one only after a series of qualitative transformations. (id., p.46; ênfase do próprio autor).

Embora admitindo que o social desempenha um papel no desenvolvimento da criança, um papel que é enfatizado quando o autor propõe as noções de mediação e de zona de desenvolvimento proximal, esse OUTRO vygotskyano aparece como já pronto, estabilizado, permanente. Pelo menos essa estabilidade e permanência é atribuída à linguagem, quando o autor discorre sobre a formação de conceitos, ao falar dos falsos conceitos:

The language of the environment, with its stable, permanent meanings, points the way that the child's generalizations will take. But, constrained as it is, the child's thinking proceeds along this preordained path in the manner peculiar to his level of intellectual development. The adult cannot pass on to the child his mode of thinking. He merely supplies the ready-made meaning of a word, around which the child forms a complex - with all the structural, functional, and genetic peculiarities of thinking in complexes, even if the product of his thinking is in fact identical in its content with a generalization that could have been formed by conceptual thinking. (VYGOTSKY, 1962, p. 68; a ênfase é minha).

Apesar de ser previsto um movimento da criança, o OUTRO que com ela interage e, nessa interação, possibilita esse movimento não se movimentaria, preso que está numa linguagem estável e já constituída.

3. No interior do Projeto Integrado e em meu projeto individual, assumimos que a relação do sujeito com a linguagem é mediada, desde sempre, pela sua relação com um OUTRO, interlocutor fisicamente presente ou representado e necessário ponto de referência para esse sujeito em constituição. Consideramos a linguagem como atividade constitutiva não apenas da subjetividade e da necessária alteridade (uma vez que, para que o sujeito se constitua como tal, precisa vivenciar um necessário encontro e contraponto com outros), mas de si própria enquanto objeto de reflexão e de análise de que se pode falar usando a própria linguagem (FRANCHI, 1977). O processo de aquisição da linguagem, tanto em suas modalidades orais quanto na escrita, é visto como parte de um mesmo processo geral de constituição da relação sujeito/linguagem. O lugar desse processo é a interlocução, entre sujeitos que se constituem em outros para seus interlocutores, constituindo-os assim como sujeitos, num constante movimento: um movimento que implica incorporação/tomada da palavra do outro ao mesmo tempo em que dela se afasta, contrapondo-se a ela para torná-la palavra própria (ver a respeito BAKHTIN, 1992). Desse movimento, por natureza não-linear, são parte integrante as hesitações, as reelaborações, as generalizações, as variações e mesmo as idiossincrasias que, a nosso ver, podem ser tomados como indícios, no sentido ginzburguiano, dos movimentos mesmos dos sujeitos em constituição. A adoção do paradigma indiciário proposto por Ginzburg (1939) permite-nos discutir o que se tem afirmado sobre o papel do OUTRO no processo de aquisição da linguagem e sua representação escrita em estudos que se baseiam em dados experimentais e em que se buscam evidências para hipóteses previamente estabelecidas. Valendo-nos de dados naturalisticamente coletados, buscamos neles indícios, marcas deixadas pelo SUJEITO, e pelo OUTRO que com ele interage, nos movimentos mesmos dessa interação.

4. Pretende-se, aqui, analisar um evento singular de interação mãe-criança pré-escolar, em que a produção escrita da criança se constitui em foco de atenção conjunta da díade, com o objetivo de discutir o papel do adulto, interlocutor letrado, no processo de atribuir sentido à seqüência de letras que a criança desenha, bem como modificações introduzidas pelo próprio modo de agir da criança no modo de agir de seu interlocutor letrado. 
O evento a ser discutido faz parte de anotações em diário mantidas pela mãepesquisadora das interações de L. com a escrita e adultos letrados a partir de um ano de idade da criança. Foi observado quando L. tinha já quatro anos, nove meses e dez dias: a criança estivera envolvida na atividade de escrever, desenhando seqüências de letras, pela manhã, enquanto esperava o ônibus que a levaria para a escola, e ao voltar retomara a atividade, colocando a mãe no papel de leitor do que ela escrevia. O produto dessa escrita é o que se segue:

\section{ESCANEAR FIGURA}

Por essa época, era comum a criança se excercitar no desenho de letras do alfabeto, desenhando sequiências delas e pedindo que o adulto lesse "o que eu escrevi aqui". Ou seja, era comum a criança colocar-se no papel de produtora de uma escrita, atribuindo ao adulto, que com ela interagia, o papel de leitor dessa produção que ela mesma se recusava a ler. O adulto, por sua vez, ao tentar ler essas sequiências idiossincráticas de letras, costumava destacar porções que fizessem sentido, cobrindo com as mãos as letras circundantes e que não interessavam, lendo enfaticamente as palavras da língua que ocasionalmente e por puro acaso surgiam no meio dessas sequiências. Isto acontecera em relação à produção da criança exibida acima, por exemplo, quando L. escreveu MIAU e PIPOCA. Nessas ocasiões era comum o adulto sugerir que a criança deixasse espaços em branco separando essas porções de sentido, uma exigência que, na certa, ainda não fazia sentido para a criança, mas que a levava a reagir, utilizando recursos variados, criações locais, para atender essa exigência.

A criança aparentemente já constituíra a idéia de que se usam letras para escrever, letras variadas e colocadas numa ordenação horizontal; sabia também que seqüências de letras, quando escritas por um adulto ou presentes num livro, revista, cartaz, ou rótulos de objetos, diziam alguma coisa, tanto que era comum trazer escritas para serem lidas, perguntar sobre escritas que via, pedir ao adulto que escrevesse algo para ela, etc. No entanto, quando a própria criança assumia o papel de produtora e se lhe perguntava "o que você vai escrever?" ela se calava ou dizia "não sei" ou "nada não"; e quando a pergunta era "o que você escreveu?" a resposta invariável era "você que lê".

Transcrevo, em seguida, parte do longo diálogo que acompanhou a produção dessa atividade de desenhar letras (os turnos foram numerados para facilitar sua referência):

$M$. pergunta a $L$. se ela quer escrever mala e ela responde não, mas logo em seguida desenha a letra $M$ e a letra A, que a mãe lê ma, que L. repete.

T1. M.: Ma! O que que você vai escrever agora?

T2. L.: Mala.

T3. M.: Então faz um ele e um a e fica mala.

T4. L.: (L. faz a letra L)

T5. M.: Mal.Você escreveu mal.

T6. L.: Eu quero mala!

T7. M.: Então faz um a.

T8. L.: Como?

T9. M.: $O$ a, do telhadinho, né?

T10. L.: (L. desenha a letra A)

T11. M.: Mala.

T12. L.: (L. desenha a letra I)

T13. M.: Malái.

T14. L.: Malái. Malái. Oh! Malaí.

T15. M.: Que que é malaí? 
T16. L.: Aí, oh, mala aî! (com ênfase no aí, fazendo gesto indicativo, tentando mostrar/explicar o aí; em seguida, L. desenha a letra $O$ )

T17. M.: Maláio. [Mala aí, ô!]

T18. C.: [Se fizer um bê dá balaio] (os [ ] indicam que a fala de C, uma outra criança de dez. anos, que no momento se encontrava na cozinha sendo que M. e L.estavam na copa, foi simultânea à fala de $M$.)

T19. L.: (L.desenha a letra A)

T20. M.: Malaióa.

T21. L.: (L..desenha a letra I)

T22. M.: Malaioái.

T23. L.: (L. desenha a letra P)

T24. M.: Malaioáip.

T25. L.: Oh! Eu escrevi tia Pi! (mostrando a letra P que acabara de desenhar)

T26. M.: Não. Cê escreveu o pê, que é a letra da tia Pi, mas cê tem que fazer o i prá ficar pi.

T27. L.: Qual que é o i?

T28. M.: Aquela do pauzinho com o pinguinho.

T29. L.: (L. desenha a letra I)

T30. M.: Malaioaípi. Oh! Você escreveu "Mala aí, oh, aí, Pi!"

T31. L.: repete entusiasmada "Oh! Eu escrevi 'Mala aí, oh, aí Pi.",

O diálogo acima mostra que L., após se recusar a escrever o que a mãe sugerira, desenha as letras $M$ e $A$, freqüentes em sua produção e parte do repertório limitado de letras que sabia desenhar. Pode até ser que a escrita fosse uma resposta à sugestão materna de escrever mala; ou seja, o produto $M A$ permitiria uma interpretação ferreiriana de escrita silábica. Não há, no entanto, nenhum indício de que a criança atribuísse às letras o valor de sílabas.

Há, por outro lado, indícios para uma outra hipótese. O $M$ e o $A$ aparecem grafados anteriormente (ver a produção escrita de L. exibida acima), embora em nenhuma das três ocasiões na seqüência $M A$ : após o $M$ aparece o $I$, seguido do $A$ por duas vezes e por $U$ na terceira ocorrência. Ao que tudo indica, tendo produzido, por acaso, a sequiência $M I A U$, logo que se pôs a desenhar letras, uma seqüência que faz sentido em português e que foi lida pela mãe, sendo a leitura recebida entusiasticamente por L., a criança tentava, mais uma vez, repetir a mágica de escrever miau (veja-se a seqüência: MIAU/MIAU/MIU/MA, na produção escrita apresentada acima).

Essas letras, escritas na seqüência MA, compõem, do ponto de vista de quem já conhece a escrita alfabética do português, a sílaba escrita ma. Pode-se supor que L. passa a aceitar a sugestão de escrever mala ao ouvir a leitura que a mãe faz desta seqüência, que faz sentido para o adulto, tanto por constituir-se isoladamente numa palavra da língua portuguesa, $m a ́$, quanto por constituir-se em segmento escrito constitutivo de outras palavras da língua, entre as quais a palavra sugerida, mala. Atendendo instrução da mãe (T3), L. escreve a letra $L$ (conhecida nessa época como "o ele da Lia"), e a sequiência $M A L$, também uma palavra escrita da língua, é lida pelo adulto, que ainda reforça (T5) "Você escreveu mal"; L. protesta (T6) "Eu quero mala", sendo instruída, então, sobre o que fazer para obter a escrita de mala (T8 a T11).

Quando L., em seguida, desenha a letra $I$, a seqüência de letras MALAI deixa novamente de fazer sentido, do ponto de vista do adulto letrado, e é lida como malái, com acentuação paroxítona, a mais produtiva em língua portuguesa (T13). Essa fala do adulto é retomada pela criança, no T14, sendo repetida por duas vezes, antes que L. exclame "Oh!" $e$ altere a acentuação para oxítona, dizendo "malaí". Essa fala da criança leva o adulto a perguntar "Que que é malaí?" (T15). Malaí, para o adulto, não é nada. É preciso que L. explique, e ela o faz (T16), pronunciando enfaticamente o aí (“Aí, oh, mala aî") e usando de 
gestos de apontar. Mala aí teria sentido para o adulto, mas, do ponto de vista letrado, a letra $A$ teria que ser repetida na escrita, e um espaço em branco deveria estar presente entre o $A$ final de $M A L A$ e o inicial de $A I ́$, para que esse sentido fosse garantido na escrita.

Negociado um sentido para a seqüência escrita MALAI, a criança segue desenhando a letra $O$, produzindo uma sequiência, $M A L A I O$, que, novamente, não faz sentido para o letrado, e é lida com a acentuação paroxítona, como maláio. Essa leitura do adulto leva uma outra criança, C., mais velha e já alfabetizada, ao comentário "Se fizer um bê dá balaio" (T18), simultâneo à fala da mãe (T17) "Mala aí, ô". Ou seja, ouvindo a leitura "maláio", um letrado propõe uma troca de letras para produzir algo que faça sentido ("balaio"); o outro letrado, que via a escrita da criança e que pouco antes negociara com ela o sentido a ser dado a uma seqüência produzida, reformula sua leitura para produzir um sentido.

Pode-se dizer que é o fato de a criança ter atribuído, no T14, um sentido à sequiência MALAI ("mala aî") e negociado essa leitura com o adulto, nos T15 e T16, que teria levado a mãe a mudar sua leitura de MALAIO do "maláio" para "mala aí, ô" (T17). Por sua vez, a leitura "mala aî", feita pela criança no T14, teria tido sua origem nos turnos que antecederam: na proposta recusada e depois aceita de escrever mala e em todo o esforço conjunto da díade para se chegar à escrita de MALA.

Instaurada uma busca de sentido para a escrita, a criança parece persistir nela. Já o adulto volta a ver a escrita da criança como simples sequiência de letras sem sentido à medida que a criança segue anexando novas letras, sem que espaços em branco separem as palavras, e as leituras feitas das seqüências MALAIOA - "malaióa" (T20); MALAIOAI - "malaioái" e MALAIOAIP - "malaioáip" são indícios disto.

É preciso que a criança intervenha novamente, na trilha da busca do sentido, inicialmente apontada pelo adulto (quando propõe "Você quer escrever X", ou pergunta "O que você vai escrever?", ou ainda quando atribui, via leitura, um sentido à sequiência de letras que por acaso constituem-se em palavras escritas), para que o adulto volte a atribuir sentido à escrita que a criança produz e que, do ponto de vista letrado, nada diria. Refiro-me ao T25, em que L. afirma, logo após grafar a letra $P$ e enquanto a aponta: "Oh! Eu escrevi tia Pi!". Para L., a letra $P$ era "a letra da tia Pi", portanto plena de sentido. Para o adulto, não basta a letra $P$ para garantir o sentido que a criança lhe atribui, e isso é negociado nos turnos seguintes (T26 a T29). A seqüência final MALAIOAIPI é inicialmente lida pela mãe como "malaioaípi", mas logo em seguida passa a ser vista como "mala aí, oh, aí, Pi".

5. Em que esse dado singular, porque representativo de uma história particular de constituição de uma representação escrita para a linguagem, apresentado acima, pode contribuir para uma discussão do papel do OUTRO no processo de aquisição da linguagem e de sua representação escrita?

No diálogo travado entre a criança e o adulto letrado, encontramos indícios de que ambos os sujeitos se movimentam: o que o adulto faz e diz tem repercussões no que a criança faz e diz e vice-versa. O adulto letrado, constituindo-se num OUTRO para o SUJEITO/criança e a confrontando com a idéia de que a escrita veicula sentidos e não é simples sequiência de letras desenhadas ao acaso, desencadeia a busca de sentidos, que se pode ver nas tentativas de L.: a) de repetir a escrita de MIAU; b) de encontrar um sentido para MALAI, lida como "malái" pelo adulto e como "mala aî" pela criança; c) na própria explicação dada ao adulto do que é aí quando indagada sobre "O que é malaí?"; d) no ver, na letra $P$, que acabou de escrever, o "Tia Pi". Aliás, essa mesma busca de sentido é indiciada na fala da outra criança, já alfabetizada, ao comentar "Se fizer um bê fica balaio" que segue à leitura "maláio" feita pela mãe. Quando o adulto lê, numa sequiência de letras feita ao acaso pela criança, uma palavra como miau ou pipoca, pergunta "O que você vai escrever?" ou sugere que a criança escreva alguma coisa, ele a está confrontando com a idéia de que a escrita é (ou deveria ser) significativa. 
Por sua vez a criança, constituindo-se num OUTRO para o SUJEITO/adulto letrado, confronta-o com sua leitura sem sentido das sequiências de letras que vê a criança produzir, confrontando-o com sua própria visão de letrado: a de quem espera, na escrita, encontrar espaços em branco separando palavras. Uma exigência que só faz sentido para quem já lê e já escreve há muito tempo. Quando a criança diz "malaî" onde o adulto só vê malái, ela força o adulto a rever sua leitura, aceitando o "mala aî" oferecido pela criança como possibilidade de sentido. Isto, no entanto, viola tão fortemente o que o adulto letrado já sabe sobre a escrita que ele logo retoma a leitura sem sentido anteriormente feita, abandonando-a só depois de ser confrontado novamente com a possibilidade de a letra $P$ ser vista como "Tia Pi" - uma possibilidade que o próprio adulto levou a criança a construir, ao apresentar essa letra para a criança como "a letra da tia Pi" em interações freqüentes, ocorridas anteriormente na história dessa díade (a esse respeito ver Mayrink-Sabinson, 1991). Nesse caso é a lembrança do sentido, atribuído pela criança à sua escrita sem sentido, que vai-se constituir no OUTRO que leva o adulto a ler "mala aí, ô" para o $M A L A I O$ e "mala aí, ó, aí, Pi" para a seqüência final MALAIOAIPI.

O que o dado acima mostra é que o SUJEITO/OUTRO está em constante movimento, seja ele um aprendiz de escrita em busca de autonomia ou um letrado já de muito tempo. E o movimento de um SUJEITO/OUTRO afeta o movimento do OUTRO/SUJEITO que, no processo de interlocução, com ele se encontra e se confronta. Teorias que se pretendem como explicativas do processo de aquisição da linguagem escrita devem, então, não só atribuir papel constitutivo ao interlocutor/OUTRO como aos outros OUTROS com os quais a criança interage, mas também permitir explicar esse movimento de constituição recíproca.

\section{BIBLIOGRAFIA}

ABAURRE, M.B.M.; MAYRINK-SABINSON, M.L.T.; FIAD, R.S. A relevância teórica dos dados singulares na aquisição da linguagem escrita. Projeto CNPq, 1992 (mimeo).

BAKHTIN, M.M. Estética da Criação Verbal. São Paulo, Martins Fontes, 1992.

FERREIRO, E.; TEBEROSKY, A. (1979). Psicogênese da Língua Escrita. Porto Alegre, Artes Médicas, 1986.

FERREIRO, E. Alfabetização em Processo. São Paulo, Cortez, 1987.

FRANCHI, C. Linguagem: atividade constitutiva. Almanaque, São Paulo, n. 5, 1977.

GINZBURG, C. (1939). Sinais: raízes de um paradigma indiciário. In: . Mitos, emblemas e sinais. São Paulo, Companhia das Letras, 1989.

MAYRINK-SABINSON, M.L.T. A respeito do reconhecimento de letras ou de como uma criança pequena pode pensar que a letra tem um proprietário. Estudos Lingüísticos; Anais do XXXIX Seminário do GEL, Franca, 1991.

VYGOTSKY, L.S. Thought and Language. Cambridge/Massachusetts, The MIT Press, 1962. Mind in Society. Cambridge/Massachusetts, Harvard University Press, 1978. 